\title{
A pilot randomized controlled trial of smoking cessation in an outpatient respirology clinic
}

\author{
Smita Pakhale MD FRCPC MSC ${ }^{1,2,3}$, Justine Baron $\mathrm{PhD}^{2,3}$, Michael A Armstrong $\mathrm{MA}^{2,3}$, Avanti Garde $\mathrm{BSC}^{2,3}$, \\ Robert D Reid PhD MBA ${ }^{2,4}$, Gonzalo Alvarez MD MPH FRCPC $1,2,3$, Debbie Aitken RN BScN ${ }^{4}$, \\ Kerri-Anne Mullen MSc ${ }^{2,4}$, George Wells PhD ${ }^{2,3,4}$, Andrew Pipe CM BA MD LLD(Hons) DSc(Hons) ${ }^{2,4}$
}

\begin{abstract}
S Pakhale, J Baron, MA Armstrong, et al. A pilot randomized controlled trial of smoking cessation in an outpatient respirology clinic. Can Respir J 2015;22(2):91-96.
\end{abstract}

OBJECTIVE: To assess the feasibility and potential effectiveness of a modified version of the Ottawa Model for Smoking Cessation in an outpatient respirology clinic.

METHODS: Adult tobacco smokers attending the respirology clinic and willing to choose a quit date within one month of enrollment were randomly assigned to receive standard care or the intervention. Standard care participants received smoking cessation advice, a brochure and a prescription for smoking cessation medication if requested. Intervention participants received a $\$ 110$ voucher to purchase smoking cessation pharmacotherapy and were registered to an automated calling system. Answers to automated calls determined which participants required nurse telephone counselling. Feasibility indicators included recruitment and retention rates, and intervention adherence. The effectiveness indicator was self-reported smoking status at 26 to 52 weeks.

RESULTS: Forty-nine (54.4\%) of 90 eligible smokers were randomly assigned to the intervention $(n=23)$ or control $(n=26)$ group. Self-reported smoking status at 26 to 52 weeks was available for 32 (65.3\%) participants. The quit rate for intervention participants was $18.2 \%$ compared with $7.7 \%$ for controls (OR2.36 [95\% CI 0.39 to 14.15]).

CONCLUSION: It would be feasible to evaluate this intervention in a larger trial. Alternatives to face-to-face follow-up at the clinic are recommended.

Key Words: Adherence; Automated calls; Feasibility; Subsidized nicotine replacement therapy; Tobacco

\section{Projet pilote aléatoire et contrôlé sur l'abandon du tabagisme dans une clinique de consultations externes en pneumologie}

\begin{abstract}
OBJECTIF : Évaluer la faisabilité et l'efficacité potentielle d'une version modifiée du Modèle d'Ottawa pour l'abandon du tabac dans une clinique de consultations externes en pneumologie.

MÉTHODOLOGIE : Des fumeurs adultes qui fréquentaient la clinique de pneumologie et qui étaient prêts à choisir une date d'abandon dans le mois suivant leur inscription ont été répartis au hasard entre des soins standards et l'intervention. Les participants aux soins standards ont reçu des conseils d'abandon du tabac, une brochure et une prescription de médicaments pour l'abandon du tabac, s'ils la demandaient. Les participants à l'intervention ont reçu un coupon de 110 \$ pour acheter des médicaments pour l'abandon du tabac et ont été inscrits à un système d'appels automatisé. Les réponses aux appels automatisés permettaient de déterminer les participants qui avaient besoin des conseils téléphoniques d'une infirmière. Les indicateurs de faisabilité incluaient les taux de recrutement et de rétention, ainsi que le respect de l'intervention. Le tabagisme signalé par les participants entre 26 et 52 semaines servait d'indicateur d'efficacité.

RÉSULTATS : Quarante-neuf (54,4\%) des 90 fumeurs admissibles ont été répartis au hasard entre le groupe d'intervention $(n=23)$ et le groupe témoin $(n=26)$. Trente-deux participants $(65,3 \%)$ ont fait connaître leur tabagisme entre 26 et 52 semaines. Le taux d'échec des participants du groupe d'intervention s'élevait à 18,2\% par rapport à $7,7 \%$ du groupe témoin (RC 2,36 [95 \% IC 0,39 à 14,15]).
\end{abstract}

CONCLUSION : Il serait faisable d'évaluer cette intervention dans une étude plus vaste. D'autres possibilités sont recommandées en plus du suivi en clinique.
$\mathrm{T}$ obacco is a leading preventable cause of death globally and is a major risk factor for respiratory-related conditions $(1,2)$. Responsible for $36 \%$ of all deaths from respiratory diseases (3), tobacco smoking is related to the progression of respiratory diseases and poor clinical outcomes $(2,4-7)$. Smoking cessation results in improvements in respiratory symptoms, airway inflammation, lung function (8-12) and prognosis (13). Quit rates among individuals with respiratory diseases, however, remain low $(2,14,15)$ and smoking is prevalent in $20 \%$ to $35 \%, 38 \%$ to $77 \%$ and $24 \%$ to $60 \%$ of adults with asthma (16-19), chronic obstructive pulmonary disease (COPD) (20), and newly diagnosed lung cancer (4), respectively.

While smoking cessation studies involving COPD subjects recruited outside of chest clinic settings have been found to be cost effective (21), little research has focused on patients attending chest clinics (22). The combined use of pharmacotherapy and individual counselling has been found to be the best approach in individuals with respiratory diseases $(14,22,23)$. Telephone counselling allows for support to be maximized around a predetermined quit date and to fit peoples' needs (24). Lower socioeconomic status is a risk factor for respiratory diseases and tobacco dependence (25), and the cost of smoking cessation aids can be a barrier to their use (26). Interventions targeting individuals with respiratory diseases may benefit from including subsidized pharmacotherapy.

The Ottawa Model for Smoking Cessation (OMSC) (27) is a clinical approach to tobacco dependence treatment found to increase smoking abstinence by an absolute $11 \%$ in hospitalized patients (28). Implemented in $>300$ Canadian health care sites, the OMSC incorporates the '5As' approach to consultation (Ask, Advise, Assess, Assist and Arrange), pharmacotherapy and follow-up support though an automated telephone triage system to link smokers requiring assistance to nurse specialist counselling. A modified version of the OMSC adapted for outpatients has been tested in a stroke prevention clinic (29); however, no such study has been conducted in an outpatient population with respiratory diseases. Smoking cessation is the only intervention that can slow disease progression in individuals with respiratory diseases such as COPD, and should be an integral component of every service for pulmonary patients (24). Therefore, evidence regarding the effectiveness of smoking cessation programs in this specific population is needed.

The purpose of the present pilot study was to determine the feasibility and potential effectiveness of an adapted outpatient version of the OMSC in a tertiary care respirology clinic. Two adaptations were made to the OMSC: a prequit date call was added to the automated calling system schedule seven days before the quit date; and access to subsidized pharmacotherapies was provided to outpatients. Data collected during the present feasibility study will be used to identify adaptations required to the study design and procedures. Data regarding recruitment, retention and the effect size will be used to determine the sample size for a larger efficacy trial.

${ }^{1}$ The Department of Medicine, The Ottawa Hospital; ${ }^{2}$ University of Ottawa; ${ }^{3}$ Ottawa Hospital Research Institute; ${ }^{4}$ University of Ottawa Heart

Institute, Ottawa, Ontario

Correspondence: Dr Smita Pakhale, The Ottawa Hospital, 501 Smyth Road, Ottawa, Ontario K1H 8L6.

Telephone 613-737-8899,fax-613-739-6807, e-mail spakhale@ohri.ca 


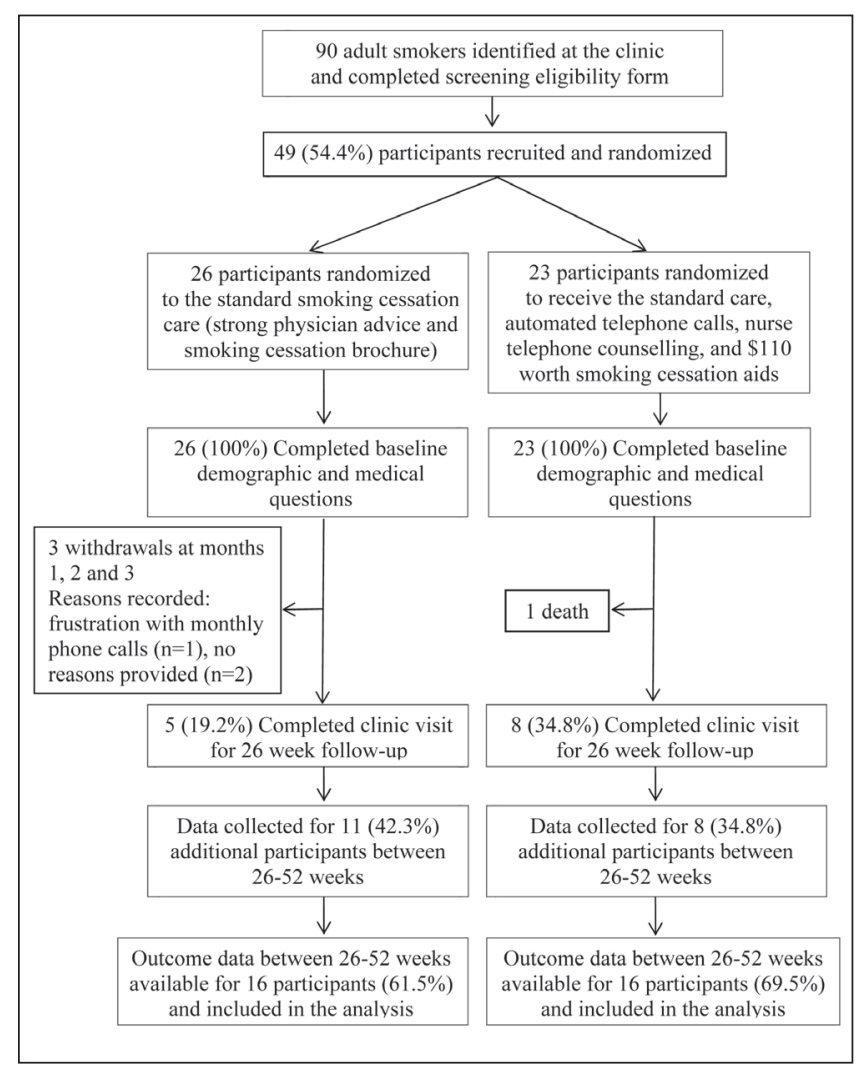

Figure 1) CONSORT diagram of the study flow

\section{METHODS}

Setting

The present project was completed at the Ottawa Hospital with support from the University of Ottawa Heart Institute (UOHI), Ottawa, Ontario. Approval was obtained from the Ottawa Hospital Health Science Network Research Ethics Board.

\section{Participants}

Adult smokers $\geq 18$ years of age who smoked tobacco in the past seven days and attended the Respirology Clinic at the Ottawa Hospital and were willing to set a quit date within one month were recruited. Subjects with a life expectancy $<2$ years, and individuals unable to speak English or French were excluded.

\section{Research design}

The present analysis was a parallel, two-group, open-label feasibility study with random assignment to control or intervention group described below.

Recruitment: The clinic team identified smokers and were asked to complete a screening eligibility form by a clinic nurse or a research team member. This form included smoking-related questions (smoking in past seven days, years smoked, amount smoked daily, confidence in and importance of quitting, number of quit attempts in the past year). Those who met the eligibility criteria and were interested were given more information and invited to sign a consent form.

Randomization, blinding and allocation concealment: Randomization was performed immediately after enrollment. Sealed and opaque envelopes were prepared by UOHI using a computer-generated allocation sequence based on stratified (according to sex) block randomization. Those responsible for randomization were unaware of upcoming group assignments. Blinding of participants was not possible due to the nature of the intervention.

Control group: Participants received the standard smoking cessation treatment including strong physician advice, an information brochure on smoking cessation aids and a prescription for pharmacotherapy if requested. Participants were invited to set a quit date within one month. They were free to use the smoking cessation programs in the city of Ottawa. The intervention was offered to control group participants at study completion.

Intervention group: In addition to standard care, intervention participants received a brief counselling session on the pros/cons of smoking, potential challenges to quitting, smoking triggers and encouragement. They received a voucher for $\$ 110$ toward the purchase of four to five weeks' worth of pharmacotherapy (nicotine replacement therapy [NRT], bupropion, varenicline). Participants were registered to an automated calling system that made nine calls scheduled seven days before their set quit date, and three, 14, 30, 60, 90, 120, 150 and 180 days after. The system made a maximum of two daily call attempts over four days. During calls, participants were asked about their smoking status, confidence in being able to remain smoke-free and forms of smoking cessation support used. The calling system flagged participants who relapsed but wanted to make another quit attempt or those with low confidence. Nurse telephone counselling was delivered to participants who were flagged within $48 \mathrm{~h}$ by specialist nurses at UOHI. Nurses also telephoned participants who reported adverse events or who did not respond to automated calls.

Data collection: Baseline data consisted of smoking-related questions in the screening eligibility form and a baseline questionnaire completed at enrollment on sociodemographic factors (age, sex, ancestry, education, employment, marital status, living status and approximate income). Research personnel made monthly calls to participants to record their smoking status and use of pharmacotherapy. No support was provided during these calls.

For the final follow-up at 26 weeks, it was initially intended to meet face-to-face with participants to record self-reported smoking status and to collect a carbon monoxide (CO) sample. It became apparent that clinic attendance for this purpose was inconvenient for many participants, resulting in missing data. A decision was made to forego biochemical confirmation and to collect self-reported smoking status using telephone contact or by meeting participants at their next scheduled clinic visit. These changes resulted in delays, and outcome data presented in the present article were collected between 26 and 52 weeks.

\section{Outcomes}

Feasibility: Feasibility indicators included recruitment and retention rates, and adherence to intervention components (voucher use and response rates to automated and nurse counselling calls).

Self-reported smoking status: Self-reported smoking status was the primary indicator of effectiveness and was obtained at 26 to 52 weeks. Participants were asked to consider their smoking behaviour over the past month and respond 'yes' or 'no' to the question "Do you still smoke?"

\section{Data analysis}

Comparisons between groups were performed using using $\chi^{2}$ tests, Fisher's exact tests, Student's $t$ tests and Mann-Whitney U tests, depending on the distribution and nature of the data. An effectiveness analysis on self-reported smoking status was conducted using a Fisher's exact test and an OR was computed adjusting for clinically significant variables. All participants, with the exception of those who were deceased or had moved to an untraceable address, were included in the analysis. Participants with missing self-reported smoking status data at 26 to 52 weeks were considered to be smokers according to the Russell Standard (30).

\section{RESULTS}

\section{Participant recruitment and loss to follow-up}

Figure 1 presents a CONSORT diagram of the study flow. Forty-nine of $90(54.4 \%)$ respirology patients identified as smokers at their routine respirology clinic appointments between November 2011 and December 2012 were enrolled and randomized. Three (6.1\%) participants, all 
TABLE 1

Baseline characteristics

\begin{tabular}{|c|c|c|c|c|c|c|c|}
\hline \multirow[b]{2}{*}{ Characteristic } & \multicolumn{2}{|l|}{ Eligible } & Study & \multirow{2}{*}{$\begin{array}{c}\text { Control } \\
(n=26)\end{array}$} & \multicolumn{3}{|c|}{ Intervention } \\
\hline & nonparticipants $(n=41)$ & $\mathbf{n}$ & participants $(n=49)$ & & $\mathbf{n}$ & $(n=23)$ & $\mathbf{n}$ \\
\hline Age, years, mean \pm SD & $59.4 \pm 10.9$ & 33 & $49.8 \pm 11.3$ & $50.9 \pm 10.4$ & 26 & $48.6 \pm 12.3$ & 23 \\
\hline Male sex & 43.9 & 41 & 49 & 50 & 26 & 47.8 & 23 \\
\hline Caucasian & - & & 83.7 & 88.5 & 24 & 78.3 & 21 \\
\hline Married & - & & 18.4 & 11.5 & 24 & 26.1 & 21 \\
\hline Live alone & - & & 28.6 & 30.8 & 23 & 26.1 & 21 \\
\hline Education & - & & & & 25 & & 21 \\
\hline High school or less & - & & 61.2 & 65.4 & & 56.5 & \\
\hline More than high school & - & & 32.7 & 30.8 & & 34.8 & \\
\hline Annual income, $\$$ & - & & & & 23 & & 21 \\
\hline$<16,000$ & - & & 46.9 & 46.2 & & 47.8 & \\
\hline$\geq 16,000$ & - & & 42.9 & 42.3 & & 43.5 & \\
\hline \multicolumn{8}{|l|}{ Smoking variables } \\
\hline Other smokers in home & 53.8 & 39 & 59.1 & 61.5 & 25 & 56.5 & \\
\hline Cigarettes/day, median & 13 & 41 & 15 & 13 & 26 & 15 & 23 \\
\hline Years smoking, mean \pm SD & $41.1 \pm 13.6$ & 41 & $33.5 \pm 12.4$ & $36.2 \pm 10.7$ & 26 & $30.5 \pm 13.8$ & 23 \\
\hline Minutes to first cigarette, median & 15 & 41 & 15 & 15 & 26 & 30 & 23 \\
\hline Quit attempts in past 12 months, median & 0.5 & 40 & 1 & 1 & 25 & 1 & 23 \\
\hline Quitting importance*, median & 4 & 41 & 5 & 5 & 26 & 5 & 23 \\
\hline Quitting confidence ${ }^{\dagger}$, median & 2 & 41 & 3 & 3 & 26 & 4 & 23 \\
\hline
\end{tabular}

Data presented as \% unless otherwise indicated. Total sample sizes of respective groups were used as denominators used to calculate percentages. Eligible nonparticipants are described using the screening eligibility form data. Cells containing '-' refer to data that were not collected on the screening eligibility form. *On a scale of 1 to 5 , how important is it to you to quit smoking/remain smoke-free? ( $5=$ most important); †On a scale of 1 to 5 , how confident are you that you can quit smoking/remain smoke-free? (5 = most confident)

TABLE 2

Voucher use and response rates to automated and nurse counselling calls

\begin{tabular}{|c|c|c|c|c|}
\hline & Total & Reached & Flagged for counselling & Received nurse counselling* \\
\hline \multicolumn{5}{|l|}{ Voucher use } \\
\hline Received $\$ 110$ voucher & $23(100)$ & & & \\
\hline Used $\$ 110$ voucher & $20(86.9)$ & & & \\
\hline \multicolumn{5}{|l|}{ Automated calling system } \\
\hline Registered with the calling system, $n$ & 23 & - & - & - \\
\hline Opted out of calling system, $n$ & 4 & - & - & - \\
\hline Call -7 days to quit date & - & $12(52.2)$ & $6(26.0)$ & $3(50)$ \\
\hline Call +3 days post quit date & - & $12(52.2)$ & $8(34.8)$ & $7(87.5)$ \\
\hline Call +14 days after quit date & - & $10(43.5)$ & $8(34.8)$ & $7(87.5)$ \\
\hline Call +30 days after quit date & - & $10(43.5)$ & $6(26.1)$ & $3(50)$ \\
\hline Call +60 days after quit date & - & $12(52.2)$ & $9(39.1)$ & $7(77.8)$ \\
\hline Call +90 days after quit date & - & $8(34.8)$ & $6(26.1)$ & $3(50)$ \\
\hline Call +120 days after quit date & - & $6(26.1)$ & $4(17.4)$ & $3(75)$ \\
\hline Call +150 days after quit date & - & $6(26.1)$ & $3(13.0)$ & $2(66.7)$ \\
\hline Call +180 days after quit date & - & $6(26.1)$ & $3(13.0)$ & $2(66.7)$ \\
\hline
\end{tabular}

Data presented as $n(\%)$ unless otherwise indicated. *Percentages presented are relative to the number of participants flagged for counselling in each call

from the control group, withdrew from the study. Frustration with monthly phone calls was the reason provided for one withdrawal, and no reason was recorded for the remaining two withdrawals. One participant in the intervention group died for reasons unrelated to the study. Loss to follow-up at 26 to 52 weeks was not statistically different between the control $(27.3 \%)$ and intervention (38.5\%) groups.

Participant characteristics

Table 1 summarizes the baseline characteristics of study participants and eligible nonparticipants. Missing data were not imputed. Eligible nonparticipants were significantly older $(\mathrm{P}<0.001)$, had smoked for significantly longer $(\mathrm{P}=0.007)$, believed it was less important to quit smoking $(\mathrm{P}<0.001)$ and were less confident to quit $(\mathrm{P}=0.004)$. Baseline differences between the intervention and control group were nonsignificant.
Intervention adherence

Twenty (86.9\%) of the 23 intervention group participants used their $\$ 110$ voucher to purchase pharmacotherapy; the mean $( \pm \mathrm{SD})$ amount spent on pharmacotherapy was $\$ 98.70 \pm 36.50$ (Table 2).

Table 2 summarizes the number of participants reached by the nine automated calls. The mean number of completed automated calls per participant was $3.5 \pm 3.2$. Seven $(14.3 \%)$ responded to 0 calls, five (10.2\%) responded to one to three calls, five $(10.2 \%)$ between four and six calls, and six (12.2\%) between seven and nine calls. The proportion of participants reached decreased over time from $52.2 \%$ to $26.1 \%$. Eleven (22.4\%) participants received at least one nurse counselling call and the mean number of times each of them were counselled by a nurse was $2.0 \pm 1.1$ (range one to nine). More than $50 \%$ of participants flagged during the automated calls subsequently received counselling. Four $(17.4 \%)$ participants opted out of the automated calling system. 
TABLE 3

\begin{tabular}{lcc} 
Effect of the intervention on self-reported smoking status \\
\hline & Control & Intervention \\
\hline Randomly assigned to treatment & 26 & 23 \\
Ineligible for inclusion in analysis & & \\
$\quad$ Deaths & 0 & 1 \\
$\quad$ Moved to unknown address & 0 & 0 \\
Eligible for inclusion in analysis & 26 & 22 \\
Complete self-reported smoking & $16(61.5)$ & $16(72.7)$ \\
$\quad$ status data, $n(\%)$ & & \\
Self-reported nonsmoker status & 2 & 4 \\
Self-reported nonsmoker rate, $\mathrm{n} / \mathrm{n}(\%)$ & $2 / 26(7.7)$ & $4 / 22(18.2)$ \\
\hline
\end{tabular}

Data presented as $n$ unless otherwise indicated

Effect on self-reported smoking status

Self-reported smoking status data at 26 to 52 weeks was available for 32 participants and are presented in Table 3. On average, these were collected 234.4 days ( 33 weeks) after baseline, with no significant difference between study groups. The number of participants reporting nonsmoker status was $18.2 \%$ in the intervention group compared with $7.7 \%$ in the control group. The OR for self-reported nonsmoker status was 2.36 (95\% CI 0.39 to 14.15). Observed differences between groups were not statistically significant $(\mathrm{P}=0.654)$.

\section{Use of pharmacotherapy}

The completion rate of the monthly telephone calls during which data regarding pharmacotherapy use were collected ranged from $32.0 \%$ to $73.9 \%$ across groups and over time. Table 4 presents the pharmacotherapy participants reported using at least once. There were no significant differences in pharmacotherapy use between study groups. Two intervention group participants used the voucher for a purchase but did not report using smoking cessation products.

\section{DISCUSSION}

We evaluated the feasibility and potential effectiveness of an adapted version of the OMSC that included an automated call triage system for delivery of nurse telephone counselling and subsidized smoking cessation medications. To our knowledge, this is the first OMSC-based intervention evaluated in an outpatient respirology population. Another adapted OMSC version without automated calls was piloted in an outpatient stroke clinic (29). Our data suggest that the intervention was associated with higher quit rates than the standard care. Differences between study groups were not significant; however, the present pilot was not powered to produce statistically conclusive results. Nonetheless, the odds of quitting smoking in the intervention group were more than double $(\mathrm{OR}=2.33)$ than in the control group and are comparable with an OR of 1.77 in a review of 123 NRT intervention studies (31). Importantly, a $10.5 \%$ absolute improvement in self-reported smoking status with our intervention would be considered to be clinically significant. The active components of the intervention, however, remain unclear. Pharmacotherapy is often delivered in combination with behavioural treatments such as telephone counselling (32). The financial incentive offered in the current study (ie, the $\$ 110$ voucher) also had the potential to influence smoking behaviours $(33,34)$. A factorial design could help examine the independent effects of each of these intervention components on smoking cessation.

The protocols used in the present study were found to be feasible with the exception of the clinic visits for the final follow-up, which did not always coincide with routine appointments. Our recruitment $(54.4 \%)$ and withdrawal $(6.1 \%)$ rates were similar to other smoking cessation studies involving outpatient populations (29,35). Furthermore, approximately $20 \%$ of studies in the literature investigating nonpharmacological interventions in subjects with respiratory conditions reported a recruitment rate $<50 \%$ (36).
TABLE 4

Pharmacotherapy use*

\begin{tabular}{|c|c|c|}
\hline & $\begin{array}{c}\text { Control } \\
(\mathrm{n}=26)\end{array}$ & $\begin{array}{c}\text { Intervention } \\
(n=23)\end{array}$ \\
\hline No pharmacotherapy used & $8(30.7)$ & $5(21.7)$ \\
\hline Pharmacotherapy use & $16(61.5)$ & $15(65.2)$ \\
\hline NRT only & $5(19.2)$ & $4(17.4)$ \\
\hline $\begin{array}{l}\text { Oral medications only (bupropion or } \\
\text { varenicline) }\end{array}$ & $8(30.7)$ & $6(26.1)$ \\
\hline $\begin{array}{l}\text { Combined use of NRT and oral } \\
\text { medication(s) }\end{array}$ & $3(11.5)$ & $5(21.7)$ \\
\hline
\end{tabular}

Response rates to the majority of automated calls remained $>43 \%$ during the first 60 days. This is slightly higher than another study (37), in which response rates to calls made 30 days after hospital discharge decreased from $52 \%$ to $30 \%$. Importantly, $85 \%$ of participants were reached at least once in our study compared with $68 \%$ in the study by Regan et al (37). It is not uncommon for response rates to telephone sessions to remain low. A review of telephone counselling interventions for smoking cessation (38) showed the proportion of participants reached and accepting telephone counselling remained small; however, those accepting telephone follow-ups had multisession support. A similar pattern was found in our study: $22.4 \%$ of the intervention group received nurse telephone counselling and the number of sessions received ranged from one to nine.

More than $85 \%$ of intervention group participants used the $\$ 110$ voucher. Our data suggest that a similar proportion of the intervention and control participants chose to use pharmacotherapy. Among those who used pharmacotherapy, a greater proportion of intervention group participants $(21.7 \%)$ reported using a combination of NRT and oral medications compared with the control group (11.5\%), although this difference was not statistically significant. These data tend to support the hypothesis that financial coverage in this population influence pharmacotherapy use and emphasizes the relevance of this approach to improve health outcomes. The proportion of control participants who used pharmacotherapy in the current study was higher than anticipated. Few smoking cessation randomized controlled trials report information regarding the use of pharmacotherapy, making comparison difficult. Previous population-based research suggests that $36 \%$ of smokers in Canada used smoking cessation pharmacotherapy in the past six months and that prescription-only medications are not used as frequently as NRT $(39,40)$, which was not found to be the case in our study. It is possible that asking control group participants to set a quit date in the present study may have contributed to an increase in pharmacotherapy use compared with the general population.

The requirement for a face-to-face clinic visit at follow-up resulted in missing data and, therefore, alternative methods of data collection were used to collect self-reported smoking status data. The rationale behind clinic visits at follow-up was to obtain timely objective validation of a self-reported nonsmoker status via exhaled CO level measurement. Nonetheless, given the importance of minimizing missing outcome data in a hypothesis-testing study, a larger study may benefit from requiring only participants with self-report of smoking cessation, or a random selection of them, to visit the clinic for a CO measurement. These methods have yielded acceptable follow-up rates $(35,41)$ and are more robust than studies not using biochemical confirmation. Financial compensation may help ensure complete $\mathrm{CO}$ data for individuals reporting smoking cessation. Alternatively, other studies have validated self-reported smoking cessation with saliva cotinine tests (35), which are a sensitive marker for determining exposure to nicotine and are preferable to $\mathrm{CO}$ tests (30). Although more expensive, saliva samples can be collected from participants by mail, and only 
participants taking NRT at the time of the cotinine level assessment and reporting a nonsmoker status would require a $\mathrm{CO}$ test to be performed (30).

There were several limitations to the present study. The small sample size was not sufficient for a statistically significant intervention effect to be detected. Larger sample sizes will be used in future trials of the intervention. The challenges we experienced to collect biochemical confirmation of self-reported smoking status meant we had to forego this outcome. There is conflicting evidence regarding the validity of self-reported smoking status in individuals with respiratory disease $(34,42)$. This may have affected our study findings, although research groups are likely to have been similarly influenced. Control participants in the current study were contacted monthly by the research team and were asked to set a quit date; it may be argued that this represents an enhanced version of standard care. The voucher provided to intervention participants was worth $\$ 110$, which is unlikely to have covered pharmacotherapy supplies for more than four to five weeks. Other programs have provided smokers with supplies of smoking cessation aids usually limited to two to eight weeks $(29,43)$. Extending access to subsidized pharmacotherapy may further improve quit rates. The present study was limited to a single site and, therefore, findings may not be generalizable to a wider population of respirology patients in different settings. Low educational and income levels in the current sample may also affect the generalizability of the

\section{REFERENCES}

1. Behr J, Nowak D. Tobacco smoke and respiratory disease.

The impact of air pollution on the respiratory tract.

ERS Journals Ltd 2002;161-80.

2. Polosa R, Thomson NC. Smoking and asthma: Dangerous liaisons. Eur Respir J 2013;41:716-26.

3. World Health Organization. World Global Report: Mortality Attributable to Tobacco. World Health Organization 2012;2012.

4. Cooley ME, Sipples RL, Murphy M, Sarna L. Smoking cessation and lung cancer: Oncology nurses can make a difference. Semin Oncol Nurs 2008;24:16-26.

5. Tammemagi CM, Neslund-Dudas C, Simoff M, Kvale P. Smoking and lung cancer survival: The role of comorbidity and treatment. Chest 2004;125:27-37.

6. Thomson NC, Chaudhuri R, Livingston E. Asthma and cigarette smoking. Eur Respir J 2004;24:822-33.

7. Ulrik CS, Frederiksen J. Mortality and markers of risk of asthma death among 1,075 outpatients with asthma. Chest 1995;108:10-5.

8. Chaudhuri R, Livingston E, McMahon AD, et al. Effects of smoking cessation on lung function and airway inflammation in smokers with asthma. Am J Respir Crit Care Med 2006;174:127-33.

9. Kanner RE, Connett JE, Williams DE, Buist AS. Effects of randomized assignment to a smoking cessation intervention and changes in smoking habits on respiratory symptoms in smokers with early chronic obstructive pulmonary disease: The Lung Health Study. Am J Med 1999;106:410-6.

10. Murray RP, Anthonisen NR, Connett JE, et al. Effects of multiple attempts to quit smoking and relapses to smoking on pulmonary function. Lung Health Study Research Group. J Clin Epidemiol 1998;51:1317-26.

11. Scanlon PD, Connett JE, Waller LA, et al. Smoking cessation and lung function in mild-to-moderate chronic obstructive pulmonary disease. The Lung Health Study. Am J Respir Crit Care Med 2000;161(2 Pt 1):381-90.

12. Willemse BW, Postma DS, Timens W, ten Hacken NH. The impact of smoking cessation on respiratory symptoms, lung function, airway hyperresponsiveness and inflammation. Eur Respir J 2004;23:464-76.

13. Parsons A, Daley A, Begh R, Aveyard P. Influence of smoking cessation after diagnosis of early stage lung cancer on prognosis: Systematic review of observational studies with meta-analysis. BMJ 2010;340:b5569.

14. Wagena EJ, van der Meer RM, Ostelo RJ, Jacobs JE, van Schayck CP. The efficacy of smoking cessation strategies in people with chronic obstructive pulmonary disease: Results from a systematic review. Respir Med 2004;98:805-15. findings. Importantly, obtaining data on mental health and living conditions would facilitate further risk stratification. Finally, further research in this area should aim to follow the recommendation by Hughes et al $(44,45)$ to measure both point prevalence abstinence and prolonged abstinence.

ACKNOWLEDGEMENTS: The authors are grateful to the Department of Medicine, University of Ottawa, University of Ottawa Heart Institute for funding this project. They acknowledge contributions from Megan Beninger in initial data collection and Lara Bajar in continued administrative support. The authors also thank Drs Shawn Aaron and Nha Voduc for allowing them to enroll subjects from their respirology clinics, and to all study participants who, with their consent, made this study possible.

AUTHOR CONTRIBUTIONS: SP is the guarantor and primary author of the article and contributed to concept, design, implementation, analysis and writing. JB contributed to data cleaning, analysis and writing. RDR and GA contributed to concept, design, data analysis and writing the manuscript. AG and MAA contributed to implementation, data collection, data entry, data cleaning and writing. DA, KAM, GW and AP contributed to concept, design and writing.

DISCLOSURES: The authors have no financial disclosures or conflicts of interest to declare.
15. Wilson JS, Fitzsimons D, Bradbury I, Stuart EJ. Does additional support by nurses enhance the effect of a brief smoking cessation intervention in people with moderate to severe chronic obstructive pulmonary disease? A randomised controlled trial. Int J Nurs Stud 2008;45:508-17.

16. Eisner MD, Yelin EH, Trupin L, Blanc PD. Asthma and smoking status in a population-based study of California adults. Public Health Rep 2001;116:148-57.

17. Ikeue T, Nakagawa A, Furuta K, et al. [The prevalence of cigarette smoking among asthmatic adults and association of smoking with emergency department visits]. Nihon Kokyuki Gakkai Zasshi 2010;48:99-103.

18. World Health Organization. Global Surveillance, Prevention and Control of Chronic Respiratory Diseases: A comprehensive approach. World Health Organization; 2007.

19. Vozoris NT, Stanbrook MB. Smoking prevalence, behaviours, and cessation among individuals with COPD or asthma. Respir Med 2011;105:477-84.

20. Tonnesen P. Smoking cessation and COPD. Eur Respir Rev 2013;22:37-43.

21. Hoogendoorn M, Feenstra TL, Hoogenveen RT, Rutten-van Mölken M. Long-term effectiveness and cost-effectiveness of smoking cessation interventions in patients with COPD. Thorax 2010;65:711-8.

22. Strassmann R, Bausch B, Spaar A, Kleijnen J, Braendli O, Puhan MA. Smoking cessation interventions in COPD: A network metaanalysis of randomised trials. Eur Respir J 2009;34:634-40.

23. Pires-Yfantouda R, Absalom G, Clemens F. Smoking cessation interventions for COPD: A review of the literature. Respir Care 2013;58:1955-62.

24. Tonnesen P, Carrozzi L, Fagerstrom KO, et al. Smoking cessation in patients with respiratory diseases: a high priority, integral component of therapy. Eur Respir J 2007;29:390-417.

25. Kanervisto M, Vasankari T, Laitinen T, Heliovaara M, Jousilahti P, Saarelainen S. Low socioeconomic status is associated with chronic obstructive airway diseases. Respir Med 2011;105:1140-6.

26. Bondy SJ, Diemert LM, Victor JC, McDonald PW, Cohen JE. Assessing the reach of nicotine replacement therapy as a preventive public health measure. Chronic Dis Inj Can 2012;33:19-28.

27. Ottawa Model for Smoking Cessation. <http://ottawamodel. ottawaheart.ca/ (Accessed November 20, 2014).

28. Reid RD, Mullen KA, Slovinec D’Angelo ME, et al. Smoking cessation for hospitalized smokers: An evaluation of the "Ottawa Model". Nicotine Tob Res 2010;12:11-8. 
29. Papadakis S, Aitken D, Gocan S, et al. A randomised controlled pilot study of standardised counselling and cost-free pharmacotherapy for smoking cessation among stroke and TIA patients. BMJ Open 2011;1:e000366.

30. West R, Hajek P, Stead L, Stapleton J. Outcome criteria in smoking cessation trials: Proposal for a common standard. Addiction 2005;100:299-303.

31. Silagy C, Lancaster T, Stead L, Mant D, Fowler G. Nicotine replacement therapy for smoking cessation (Review). Cochrane Library 2008;(1):CD000146.

32. Stead LF, Lancaster T. Combined pharmacotherapy and behavioural interventions for smoking cessation. Cochrane Database Syst Rev 2012;10:CD008286.

33. Volpp KG, Troxel AB, Pauly MV, et al. A randomized, controlled trial of financial incentives for smoking cessation. N Engl J Med 2009;360:699-709.

34. Wilson JS, Elborn JS, Fitzsimons D, McCrum-Gardner E. Do smokers with chronic obstructive pulmonary disease report their smoking status reliably? A comparison of self-report and bio-chemical validation. Int J Nurs Stud 2011;48:856-62.

35. Park ER, Japuntich S, Ternel J, et al. A smoking cessation intervention for thoracic surgery and oncology clinics: A pilot trial. J Thorac Oncol 2011;6:1059-65.

36. Sohanpal R, Hooper R, Hames R, Priebe S, Taylor S. Reporting participation rates in studies of non-pharmacological interventions for patients with chronic obstructive pulmonary disease: A systematic review. Syst Rev 2012;1:66.

37. Regan S, Reyen M, Lockhart A, Richards AE, Rigotti NA. An interactive voice response system to continue a hospital-based smoking cessation intervention after discharge.

Nicotine Tob Res 2011;13:255-60.

38. Stead L, Perera R, Lancaster T. Telephone counselling for smoking cessation. Cochrane Database Syst Rev 2006;19(3):CD002850.

39. Shiffman S, Brockwell SE, Pilliteri JL, Gitchell JG. Use of smokingcessation treatments in the United States. Am J Prevent Med 2008;34:102-11.

40. Vaidya V, Hufstader-Gabriel M, Gangan N, Shah S, Bechtol R. Utilization of smoking-cessation pharmacotherapy among chronic obstructive pulmonary disease (COPD) and lung cancer patients. Curr Med Res Opin 2014;30:1043-50.

41. Rodgers A, Corbett T, Bramley D, et al. Do u smoke after txt? Results of a randomised trial of smoking cessation using mobile phone text messaging. Tob Control 2005;14:255-61.

42. Hilberink SR, Jacobs JE, van OS, et al. Validation of smoking cessation self-reported by patients with chronic obstructive pulmonary disease. Int J Gen Med 2011;4:85-90.

43. Cummings KM, Hyland A, Fix B, et al. Free nicotine patch giveaway program 12-month follow-up of participants. Am J Prev Med 2006;31:181-4.

44. Hughes JR, Keely JP, Niaura RS, Ossip-Klein DJ, Richmond RL, Swan GE. Measures of abstinence in clinical trials: Issues and recommendations. Nicotine Tob Res 2003;5:13-25.

45. Hughes JR, Carpenter MJ, Naud S. Do point prevalence and prolonged abstinence measures produce similar results in smoking cessation studies? A systematic review. Nicotine Tob Res 2010;12:756-62. 


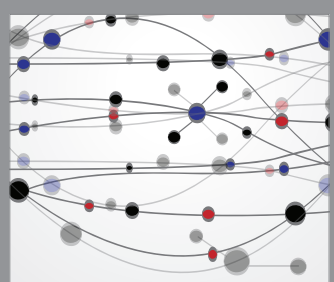

The Scientific World Journal
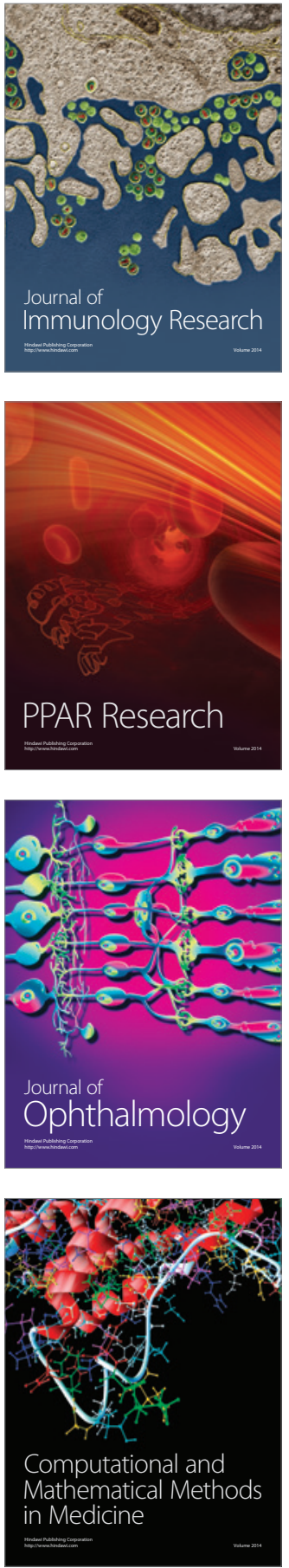

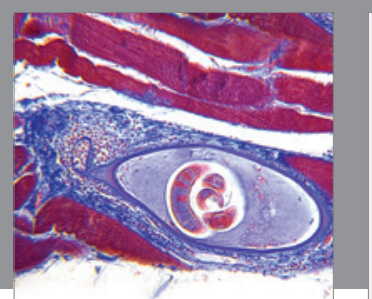

Gastroenterology Research and Practice

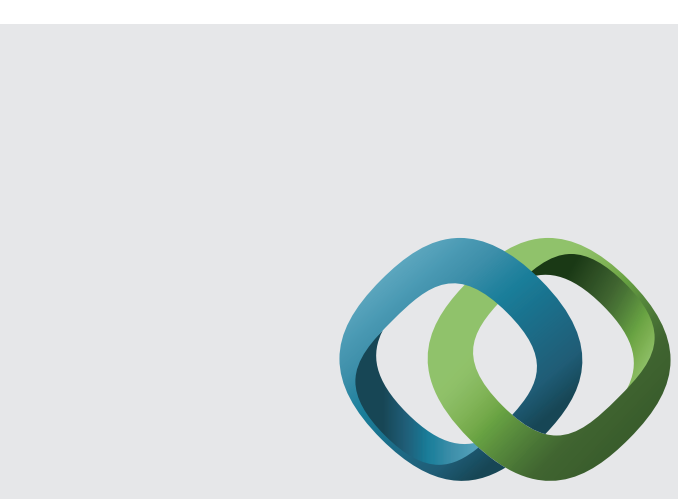

\section{Hindawi}

Submit your manuscripts at

http://www.hindawi.com
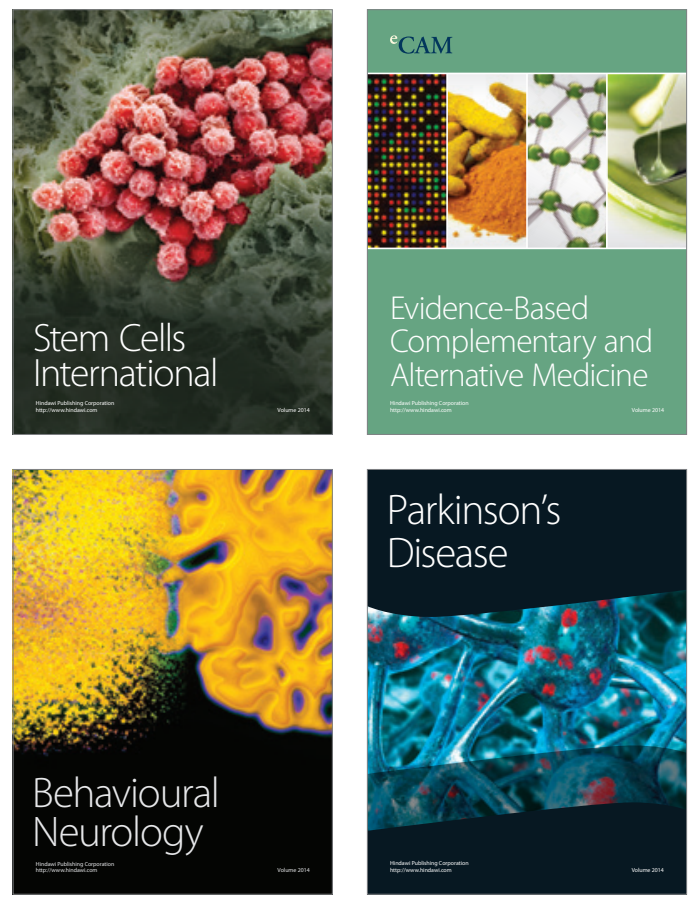
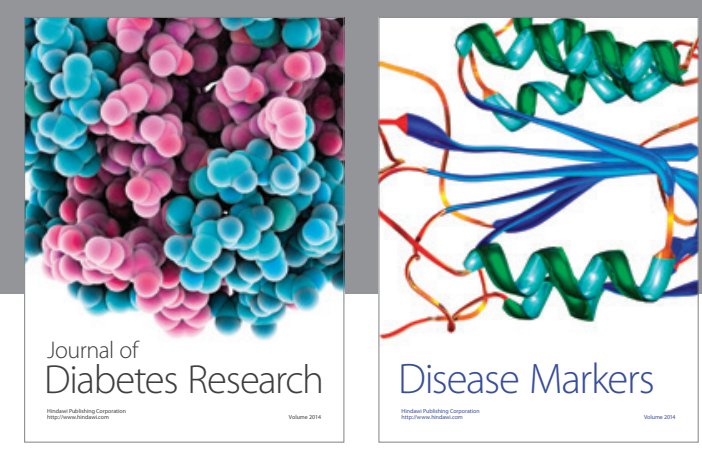

Disease Markers
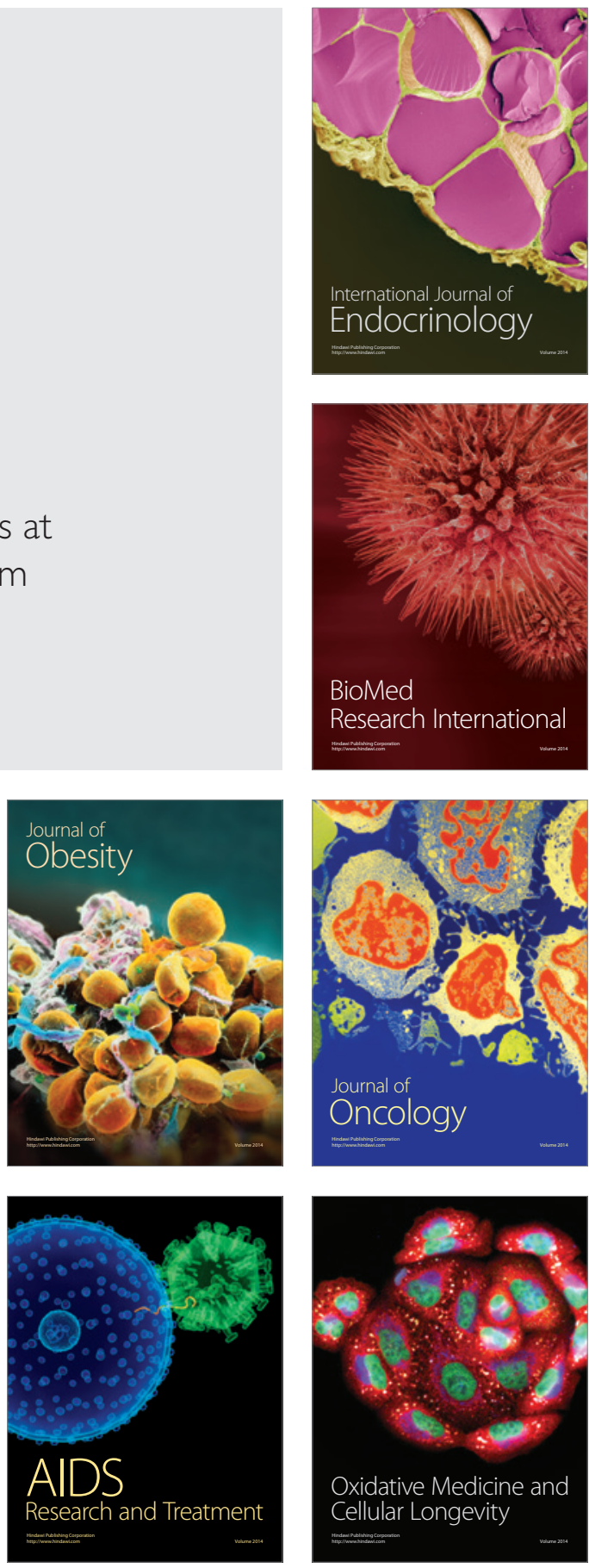